\title{
MICROBIAL FUEL CELL: AN ENERGY HARVESTING TECHNIQUE FOR ENVIRONMENTAL REMEDIATION
}

\author{
V. ANCONA ${ }^{1}$, A. BARRA CARACCIOLO ${ }^{1}$, D. BORELLO ${ }^{2}$, V. FERRARA ${ }^{3}$, P. GRENNI ${ }^{1} \&$ A. PIETRELLI ${ }^{4}$ \\ ${ }^{1}$ Water Research Institute (IRSA), National Research Council (CNR), Italy \\ ${ }^{2}$ Department of Mechanical and Aerospace Engineering, Sapienza University of Rome, Italy \\ ${ }^{3}$ Department of Information Engineering, Electronics and Telecommunications, \\ Sapienza University of Rome, Italy \\ ${ }^{4}$ Laboratoire Ampere - Universitè de Lyon - INSA Lyon - Ecole Centrale de Lyon, France
}

\begin{abstract}
Pollution of soil and water environments is mainly due to different anthropogenic factors, and the presence of organic contaminants, in particular persistent, bioaccumulative and toxic ones, arouses concern for their possible effects on environment and human health. One nature-based technology that can be used in biodegradation of contaminated soil and water is microbial fuel cells (MFCs). They are also capable of producing energy and of being used as environmental sensors. In this context, this article aims at presenting the capacity of MFCs to reduce environmental pollution by exploiting the process of bioelectrochemical utilization of organic matter via microbial metabolism, to generate usable byproducts, fuels and bioelectricity. The main characteristic of an MFC, when used for energy harvesting, is the absence of emissions of pollutant gases such as $\mathrm{CO}, \mathrm{CO}_{2}, \mathrm{SOx}$ or NOx. This characteristic, together with the intrinsic capacity of bioreactors to decontaminate soils and water, is stimulating the research into engineering solutions exploiting the MFC potential. Among the different types of MFCs, as bioelectrochemical systems (BESs), the terrestrial microbial fuel cells and the wastewater microbial fuel cells convert energy using a biocatalyst (microorganism) and a biofuel (organic substrate) in basic environments such as soil and water. Consequently, MFCs can be used as energy sources for powering sensors with low-power and low-voltage characteristics or complete single nodes of a distributed wireless sensor network, if coupled with smart although more complex electronic circuit. Moreover, MFCs can be environmental sensors, suited to monitoring some environmental parameters influencing MFC functional behaviours such as $\mathrm{pH}$ and temperature. This article introduces the polluted environment scenarios where these technologies could be suitably applied together with the description of two main types of MFC structures and their functioning. Furthermore, some case studies in which MFCs are used in decontamination of polluted environments are described.
\end{abstract}

Keywords: microbial fuel cells, disaster recovery, remediation, energy harvesting

\section{INTRODUCTION}

Many aquatic and terrestrial environments are affected by anthropogenic pollution from different sources (industrial, agricultural, etc.) including illegal and criminal actions. Several pollutants (e.g. persistent organic pollutants (POPs), hydrocarbons and pesticides) are toxic for both human and ecosystem health. Official data, updated in May 2017 by the Italian Ministry of the Environment, report 40 contaminated sites of national interest (SIN) for a total area of 241,756 hectares, of which 164,023 is land and the rest water. In this context, this article aims at introducing the microbial fuel cell (MFC), as a nature-based technology able to bring environmental remediation whilst producing energy [1,2]. An MFC is a bioreactor that converts chemical energy of chemical bonds in organic compounds into electrical energy through catalytic reactions of microorganisms under anaerobic conditions. Because of this, there is the possibility of using MFCs as energy sources, powering measuring devices for monitoring the environment and using sensors distributed throughout the territory and connected in a communication network (wireless sensor network [WSN]). MFC technology can constitute a valid and sustainable solution (it does not emit any harmful products) for 
the reclamation of contaminated areas. Moreover, MFCs can be environmental sensors. In fact, it is possible to design a system based on MFCs that simultaneously feeds acquisition boards with specialized sensors and uses the same fuel cells as sensors for detecting some environmental parameters, those that influence their functional behaviour. As the microbial activity is supported by the dispersed organic matter, the MFC itself can interestingly be considered as a contamination sensor as the reduction of cell activity suggests that the microbial activity is reduced and then that the organic matter is reduced in the soil/water.

Among the different types of MFCs, as bioelectrochemical systems (BESs), the terrestrial microbial fuel cells (TMFCs) and the wastewater microbial fuel cells (WWMFCs) convert energy using a biocatalyst (microorganism) and a biofuel (organic substrate) in basic environments like soil and water.

This paper is organized as follows. First, the environmental pollution scenarios for which MFC technology could be advantageously applied will be identified (Chapter 2), showing two specific examples of treatment of areas affected by pollution: the first one based on TMFC and the second on WWMFC. Energy harvesting performances are different for each type, and these evaluations together with physical structure of the devices, operating mode and electrical characterization will be presented in Chapter 3. Then, details of some study cases will be described (Chapter 4). Discussion and conclusion will close the paper (Chapter 5).

\section{POLLUTION SCENARIOS}

\subsection{Soil contamination}

Soil contamination is a worldwide problem [3]. The activities that mainly contribute to soil contamination are industrial and commercial (mining, oil extraction and production and power plants), agricultural (incorrect use of pesticides and fertilizers) and municipal and industrial waste disposal. POPs are extremely toxic substances for environment and human health on a world scale. There are currently 33 POPs [4], including pesticides, industrial chemicals and by-products unintentionally produced during most forms of combustion. All of them can then be found in soils and can be derived from different anthropogenic activities or from illegal dumps $[5,6]$. Waste disposal in unauthorized areas can cause several aesthetic, economic, social and, above all, environmental negative impacts, thus representing a public hazard. Illegal landfills are a great environmental problem in many countries. According to the report by the European Union Action to Fight Environmental Crime (EFFACE), the total amount of illegal landfills in EU is equal to 12,628 [7]. In particular, most European countries have illegal landfills within their territory, and Poland, Italy and Germany are the countries with the highest amount of tons of illegal waste within their territory [7]. The presence of illegal landfills generates impacts such as the deterioration of local landscapes, air, soil and aquifer pollution and can increase risks for human health [7].

\subsection{Water pollution}

The intensive processing of agricultural products for the agri-business industry usually generates a large amount of polluted water, which cannot be reused again for agricultural purposes, because of the high amount of organic pollution in the wastewater produced by this industry. 
MFCs can, for example, be a suitable solution for the depollution of wastewater from coffee processing, allowing coffee farmers a safe second utilization of the water [8,9], and at the same time a recovery of energy for the system's functioning and sensors.

\section{MICROBIAL FUEL CELLS AS ENERGY HARVESTING AND SENSORS}

The energy stored in the chemical bonds of organic compounds can be turned into electrical energy by using an MFC bioreactor. The microbial activity of MFCs is essential to producing electrons from various organic compounds in order to sustain the electricity generation.

The main characteristic of an MFC, when used for energy harvesting, is the absence of emissions of pollutant gases such as $\mathrm{CO}, \mathrm{CO}_{2}, \mathrm{SOx}$ or NOx. This characteristic, together with the intrinsic capacity of the bioreactor to decontaminate soils and water, is stimulating research into engineering solutions exploiting the MFC potential.

Several MFC structures have been developed, depending on the basic element/substrate used, i.e. chemical solutions, soil and water, and aiming at optimizing the conversion efficiency. In general, the reactor has two chambers, anode and cathode, and divided by an electrolyte ensuring the transfer of protons. At the opposite ends, there are two electrodes.

Since the presence of oxygen in the anode chamber inhibits the production of electricity, the anode chamber normally operates under anaerobic conditions. Accordingly, in the environment of the anodic chamber enriched with nutrients and in anaerobic conditions, there is a production of surplus electrons and protons due to the action of the microorganisms oxidizing the organic matter into carbon dioxide. The electrons produced flow across the electrodes in the external circuit generating a (small) electric current and are finally sent back to the cathode side of the MFC. Protons are transferred passively through water or soil to the cathode chamber. In this same chamber, protons and electrons are reacted at the same time as oxygen diminishes in water.

Different configurations are possible. In TMFCs, the soil itself plays the roles of both electrolyte and source of biodegradable organic matter. Wastewater, instead, is the source of nutrients and bacteria in WMFC. Furthermore, there are innovative reactors providing the possibility of employing other kinds of microorganisms such as mitochondrial cells or enzymes [10], [11], instead of bacteria.

The following subchapters focus on two different BES fuel cells (i.e. TMFCs and WWMFCs), specifying their physical structure, operation and energy harvesting performances. Moreover, a paragraph will be dedicated to electrical characterization of the TMFC and WWMFC devices currently being studied by the authors.

\subsection{BES technologies}

BESs, by definition, exploit the biological activity of live organisms for the reduction of pollutants, recycling of useful elements, synthesis of new products and production of electricity.

BESs are capable of converting the chemical energy of organic waste into electricity in the case of MFCs or hydrogen/chemical products in the case of microbial electrolysis cells (MECs). The materials used in building BESs are very important as they affect their performance and the durability of the system.

In the context of bioremediation of wastewater, BES technologies have attracted a lot of interest in the recent years, due to their effectiveness in depolluting and the advantage of energy recovery as a by-product of the process. 


\subsubsection{TMFCs}

The TMFCs considered in this study are standard laboratory-scale containers (microcosms) made of PVC. They have a roughly cylindrical shape whose height and diameter are $10 \mathrm{~cm}$ both. The anode and cathode electrodes are graphite fibre discs, with a diameter and thickness of about $9.2 \mathrm{~cm}$ and $0.65 \mathrm{~cm}$. respectively. Anode electrode is placed at a working depth between 6 and $8 \mathrm{~cm}$ under the ground, in order to assure anaerobic conditions, while cathode electrode is on top of soil.

The electrical performance of TMFCs depends on different parameters, principally $\mathrm{pH}$, type of bacteria, type of soil and water content.

The $\mathrm{pH}$ causes alterations in concentration of ions, membrane potential, biofilm formation and proton-motive force. A $\mathrm{pH}$ in a 6-9 range favours the proliferation of bacteria [12], so it is expected that a substrate that shows a $\mathrm{pH}$ value close to neutral should show the best performance.

We are testing TMFCs to detect the most abundant and active bacterial species inside the MFCs before and after the cell utilization. Normally, a time interval after the experiment start of 10 days is sufficient for the formation of a bacterial colony and a biofilm around the anode. The polymerase chain reaction (PCR) analysis confirmed the presence of the most popular bacteria on the TMFC anode electrode: Pseudomonas bacteria family.

Figure 2 shows the effect on maximum power produced by an MFC due to an increase in $\mathrm{pH}$ obtained by using different types of soils: acid with a $\mathrm{pH}$ equal to 5.3, clay soil $(\mathrm{pH}=6.3)$ and peaty soil with an almost neutral $\mathrm{pH}$ equal to 7.2. The figure also shows the effect of the inoculation of a pseudomonas bacterial strain resulting in an increase in the maximum power generated. The maximum power traced in Fig. 2 was obtained by adapting the resistive load to a value of $1 \mathrm{kOhm}$, equal to the internal resistance showed by the TMFC. The internal resistance of a cell is dependent on its size, chemical properties and age, and on temperature and the discharge current. It determines the electrochemical limitations to the performance of MFCs. In fact, the chemical oxygen demand (COD) is reduced more slowly when internal resistance shows higher values, revealing how fast the organic matter is consumed [13]. Another effect caused by a high internal resistance value is the different metabolism observed, with an increase in the production of short-chain fatty acids [14].

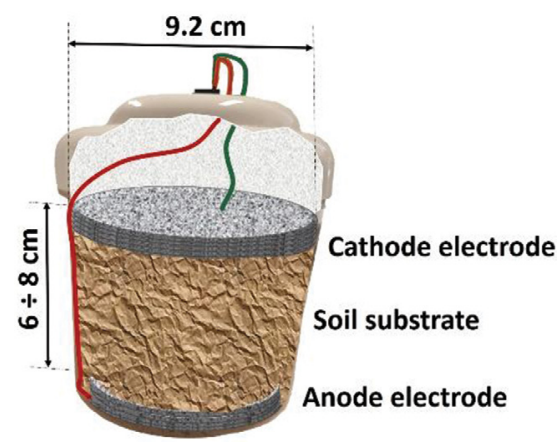

Figure 1: Standard laboratory-scale TMFCs. There is continuity between anode and cathode chambers: soil itself plays the roles of both membrane and source of biodegradable organic matter. 


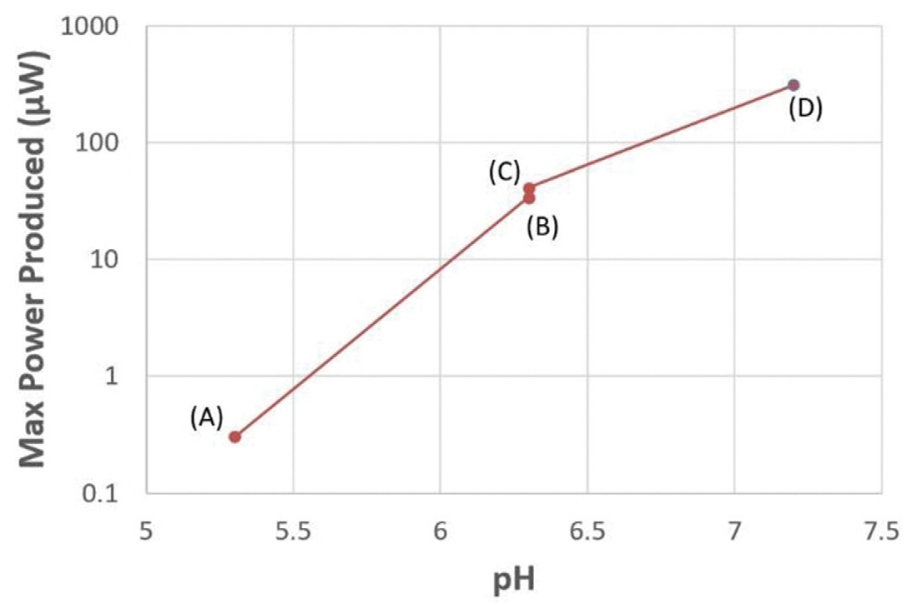

Figure 2: A neutral $\mathrm{pH}$ favours the proliferation of bacteria and increases the maximum power generated by MFCs. Types of soil and measurement specifications adopted: (A) acid soil, (B) clay soil, (C) clay soil with inoculated pseudomonas bacterial strain, (D) peaty soil.

\subsubsection{WWMFCs}

Figure 3 shows the physical structure of laboratory-scale WWMFCs: it is of a cylindrical shape and made of a $0.71 \mathrm{PVC}$ draining tube. The distance between the electrodes is about $4 \mathrm{~cm}$ with an anode made of a carbon fibre brush (30\% Teflon treated, Fuel Cell Earth LLC, USA). An air cathode of $120 \mathrm{~cm}^{2}$ of carbon cloth was manually made, using a paintbrush with $1.56 \mathrm{mg}$ of black carbon and $0.5 \mathrm{mg}$ of platinum for every $\mathrm{cm}^{2}$ of the cathode surface area The performance of WWMFCs is highly dependent on the ambient temperature and only slightly on the $\mathrm{pH}$ value of the fuel. Instead, TMFCs have a different electrical behaviour, as they are

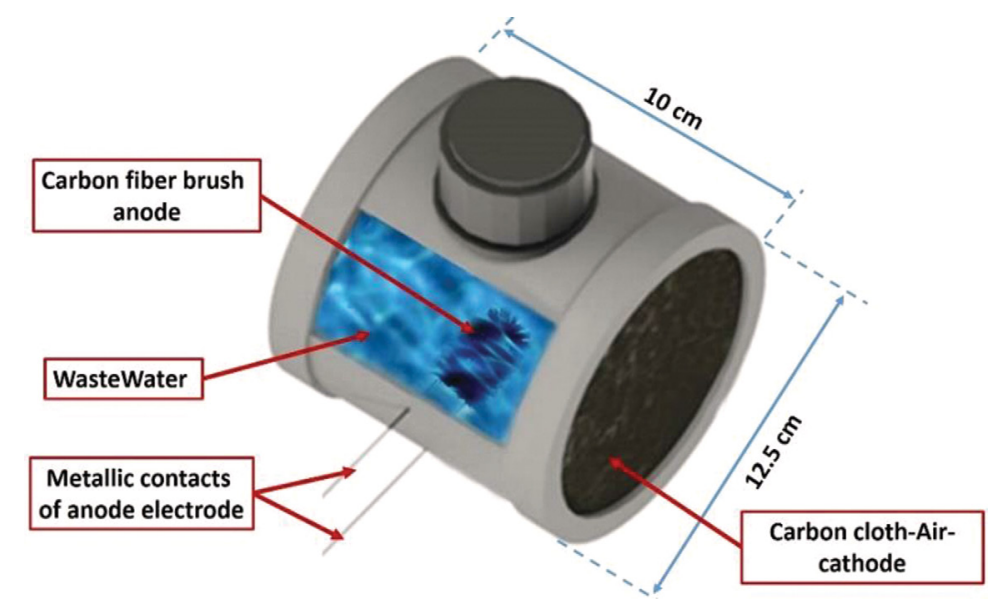

Figure 3: WWMFC laboratory-scale reactor such as that manufactured at the Laboratoire Ampere-Universitè de Lyon. 
more dependent on the $\mathrm{pH}$ of the fuel (soil) and less dependent on the ambient temperature. The power production can vary from $10 \mu \mathrm{W}$ to $900 \mu \mathrm{W}$ depending on the external conditions, the fuel (wastewater) used and the constitutive materials, with an internal resistance usually around $400 \mathrm{Ohm}$ for the configuration of a single reactor.

\subsection{MFC as power source for electronic systems.}

Table 1 shows examples of the typical load value at maximum power point (MMP) reached by a single lab-scale WWMFC or TMFC, or in the case of parallel connection of two WWMFCs. In this case, custom laboratory-scale WWMFC produces a lower power level than standard laboraotry-scale TMFCs $[15,16]$. For each of the two devices, MMP is obtained using a different resistive load value. A lower electric resistor value, used in the WWMFC configuration, assures higher current flows in the circuit, with a contemporary lower output voltage. In any case, the design of harvesting energy devices using the WWMFC technology takes advantage of a greater control of the reproducibility of the electrical performances compared to the TMFC technology. Both devices generate small-voltage values, e.g. lower than the voltage threshold of a silicon diode, the simplest electronic device in use.

In order to adopt MFCs as a power source for standard electronic circuits, albeit with lowpower and low-voltage characteristics, it is necessary to design at least one suitable DC-DC converter, such as the step-up or flyback configuration. Alternatively, an array of MFCs, arranged in series and parallel, allows the increase in voltage and current, respectively. Table 1 shows the MMP results of different configurations for a single reactor or two WWMFCs arranged in parallel. The WWMFCs were fuelled in both cases with a synthesized wastewater, and the $\mathrm{pH}$ value was imposed at 7.2 and an acetate concentration as organic content (used as organic matter to feed the reactor $0.7 \mathrm{~L}$ ), was imposed at $1 \mathrm{~g} / \mathrm{L}$. In this case, reactors have worse performance in comparison to a real urban wastewater. However, the synthetic wastewater created in the laboratory contains only what is desirable and controlled, so that it permits a more accurate and controlled testing.

A decrease in internal resistance occurs when two reactors are put in parallel configuration: MPP was found at an external load of $200 \mathrm{Ohm}$. The reduced internal impedance value can bring better performances in terms of power and current delivered due to the reduced ohmic drop. The ohmic losses are the linear resistance to the flow of electrons through the material of the electrodes and the various interconnections, as well as the resistance to the flow of ions through the electrolyte.

Table 1: Example of MMPs of WWMFC and TMFC devices.

\begin{tabular}{|c|c|c|c|c|}
\hline Cell & $\begin{array}{c}\text { Lab-scale single cell } \\
\text { external size }\left(\mathbf{d m}^{3}\right)\end{array}$ & $\begin{array}{c}\text { Power } \\
(\mu \mathrm{W})\end{array}$ & $\begin{array}{c}\text { Voltage } \\
(\mathbf{m V})\end{array}$ & $\begin{array}{c}\text { Load } \\
(\mathbf{O h m})\end{array}$ \\
\hline $\begin{array}{c}\text { Single } \\
\text { WWMFC }\end{array}$ & $\begin{array}{c}1.2 \\
\text { (0.7 litres of effective } \\
\text { capacity) }\end{array}$ & 27.5 & 105 & 400 \\
\hline Single TMFC & $\begin{array}{c}0.78 \text { (0.4 of effective } \\
\text { soil) }\end{array}$ & 310 & 557 & 1000 \\
\hline $\begin{array}{c}1.2 \\
\text { Two parallel } \\
\text { WWMFCs }\end{array}$ & $\begin{array}{r}\text { (0.7 litres of effective } \\
\text { capacity) }\end{array}$ & 112 & 149.7 & 200 \\
\hline
\end{tabular}


Considering the application of MFCs as a bioreactor, the connection of a stack of MFCs can increase the deliverable power. As already mentioned, different connections are conceivable: a serial or parallel connection or a combination of both (series/parallel).

Since a parallel connection of MFCs can increase current density compared to a single cell and is similar to scaling-up MFCs in volume, voltage value tends to the mean of that of the cells. A series connection instead provides an increase in the resultant voltage, but currents can be easily affected by cable resistance due to long wires and imperfect connections.

The design parameters of reactors are also important. Non-uniformity in their manufacturing process can result in an impedance mismatch among cells. The voltage reversal is caused by an impedance mismatch, in turn due to fuel supply, microbial or reactor non-uniformities, the impedance mismatch is the reason for voltage reversal. This is detrimental to power generation because the MFC involved absorbs the energy produced by the others.

Due to their properties, MFCs could have many different applications. As a matter of fact, the energy converted by MFCs can be utilized in a wide range of domains. Obviously, the current supplied by a single cell is sufficient at most to power simple sensors (such as temperature sensors). Nevertheless, it is possible to supply proper energy to a complete node in a WSN network, characterized by a variable power regime, by using a single TMFC or WWMFC cell. As for all electronic systems of this type, the absorption peaks are displayed at intervals of several minutes; usually MFCs are in the standby mode, while, when they are in the operating mode, they consume a low amount of power. Examples of electronic circuits implementing a variable power profile have been presented and published by authors [17].

Powering the node in a WSN allows the realization of applications such as continuous monitoring in precision farming without any environmental impact. In addition to sensors, every network node includes a transceiver for communication and generally a microcontroller for the local operation and signal processing. Generally, each network node in a WSN includes a sensor device to collect information from the environment and transmits data to the central node. The use of MFCs as biosensor devices and not only for power supply thus makes it possible to minimize the environmental impact of a network node.

\subsection{MFCs as sensors}

\subsubsection{Effect of organic substrate decay}

The effect of the substrate acts over time as its value decreases. This process can be faster if the wastewater is fuelling an MFC. The average open circuit voltage of a laboratory-scale WWMFC fuelled with urban real wastewater is $0.6 \mathrm{~V}$. Usually, the value is between $0.5 \mathrm{~V}$ and $0.7 \mathrm{~V}$ at the beginning and it goes down to $0.3 \mathrm{~V} 3$ months later due to a reduced concentration of organic substrate. It was observed after 3 months that the organic content of a real urban wastewater was reduced to $311 \mathrm{mg} / \mathrm{l}$ of total organic carbon (TOC).

The best result at an ambient temperature of $20^{\circ} \mathrm{C}$ was $490 \mu \mathrm{W}$ for a reactor fuelled with fresh urban real wastewater. Instead using the same kind of wastewater, but after waiting two months from the moment of its withdrawal, when there was a decrease in organic value, the value of power at MPP achieved during tests of $3 \mathrm{~s}$ of measurement time was $123 \mu \mathrm{W}$.

The effect was also monitored over time for synthetic wastewater created in the laboratory. The value of acetate as an organic substrate was $1 \mathrm{~g} / \mathrm{l}$ for this artificial water. The average OCV value was measured at around $300 \mathrm{mV}$ with an output power of $36 \mu \mathrm{W}$. After waiting one month, these values decreased to $200 \mathrm{mV}$ and a power of $27 \mu \mathrm{W}$ at MPP (measured during 3 s at a $400 \Omega$ load). 


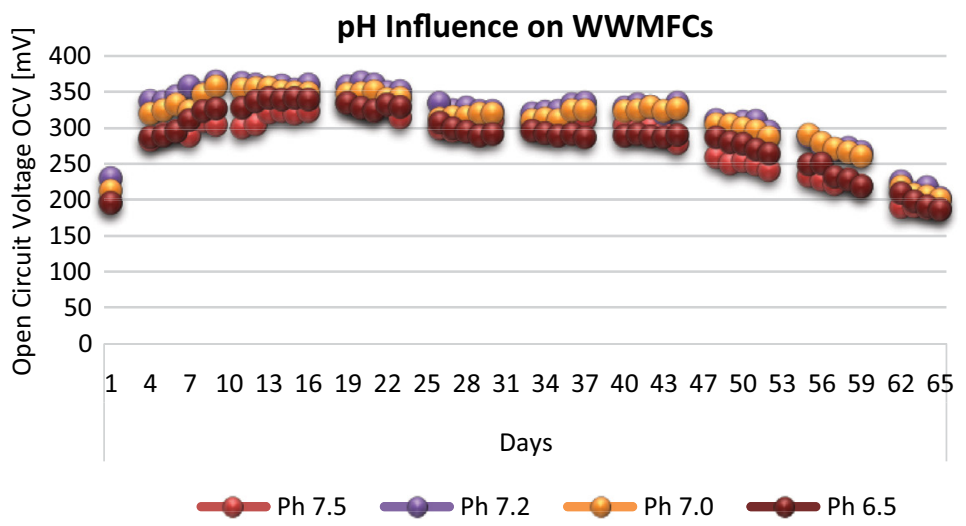

Figure 4: pH influence on OCV of WWMFCs

\subsubsection{Effect of $\mathrm{pH}$ on WWMFCs}

An experimental campaign was done on WWMFC reactors to study the effect of $\mathrm{pH}$ on energy conversion performance. The results in Fig. 4 show a slight effect of the pH value on WWMFCs, when compared to TMFCs. The $\mathrm{pH}$ value of the soil has a critical influence on TMFCs, whereas in a WWMFC with a solution of $\mathrm{pH}$ value between of 6.5 and 7.5 the effect on energy production seems not to be great. The WWMFC used in the experiments was fuelled with synthetic wastewater; four laboratory-scale reactors were tested with different imposed $\mathrm{pH}$ values: 6.5, 7, 7.2 and 7.5.

\section{MFCS TO DECONTAMINATE A POLLUTED ENVIRONMENT}

\subsection{TMFCs: a preliminary case study}

We are currently performing a case study regarding the performance of a TMFC using soil contaminated with DDE (dichlorodiphenyldichloroethylene), a DDT (dichlorodiphenyltrichloroethane) metabolite, for analysing the cell characteristics and the effectiveness in removing soil contamination. In our study, TMFCs are being tested for triggering and promoting DDE degradation in soils by stimulating exo-electrogen microorganisms that catalyse oxidation and reduction reactions in two electrodes. TMFCs should be investigated using: (a) microbiological analyses for assessing changes in the soil microbial community such as abundance (DAPI counts), viability (live/dead methods) and dehydrogenase activity (DHA) $[18,19]$ and (b) electric measurements to assess characteristic curves and power generation exploiting different configurations by changing the circuit resistance in two set-up conditions (closed or open circuit). The changes in such parameters make it possible to estimate the contaminant degradation rate.

In Fig. 5, we report the results of one of the electrical measurements carried out on a soil+DDE TMFC. The measurement starts in open circuit conditions. Every $15 \mathrm{~min}$, the circuit is closed for $5 \mathrm{~s}$ over a decreasing resistance $(10,000,5,000,3,000,1,000,500,300$ and $100 \mathrm{Ohm}$ ) and current is measured. In Fig. 5 (top), the voltage and the current measured during the test are reported. The time step set between two successive discharges is sufficient to recover the initial cell voltage almost completely. As expected, the discharge current increases when the circuit resistance decreases. 


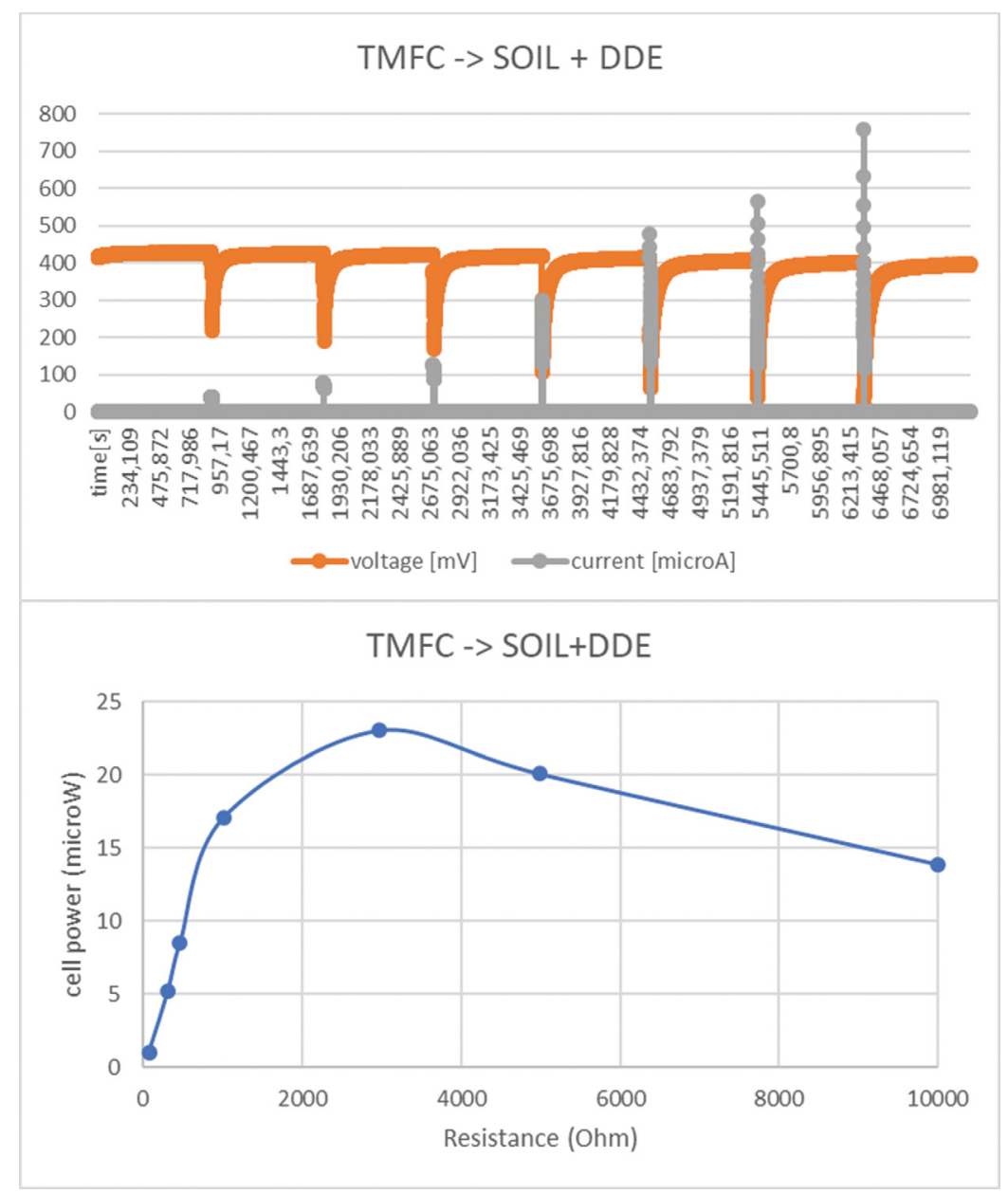

Figure 5: TMFC characteristics: (top) time variation of voltage and current; (bottom) cell power when varying the circuit resistance.

In Fig. 5 (bottom), the TMFC power, measured when varying the circuit resistance, is reported. Even if the configuration with $R=100 \mathrm{Ohm}$ shows the maximum current peak, this is not the condition of maximum power, which occurs for values of $\mathrm{R}$ ranging between 1,000 and 3,000 Ohm.

As seen above the cell has a small voltage, current and, consequently, power. Nonetheless, it is able to harvest sufficient energy to operate a simple sensor (e.g. $\mathrm{pH}$ and soil humidity) and to deliver the information to a receiver that processes the information (WSN).

\subsection{WWMFCS}

A promising application of WWMFs is cleaning up water. The reduction in the organic content present in any type of wastewater can be performed by a WWMFC. One of the principal fields of application is the agronomic industrial sector. 
As an example, the main constituent in the wastewater generated in coffee primary processing is organic matter. The COD values can be up to $80 \%$ of the pollution load, while the biochemical oxygen demand (BOD) can reach values of up to $20,000 \mathrm{ppm}$. Existing regulation for irrigation water quality in Italy are stricter than the EU guidance and consider a safe threshold [20] for a COD of $100 \mathrm{mg} \mathrm{O} / \mathrm{dm}^{3}, 1000$ times lower. Wastewater from agronomic industries can be cleaned to a safe level of organic pollution for water reuse [8,21]. For example, the wastewater generated in a coffee treatment plant can be made available for a second reuse in agriculture in less than a week when treating it with WWMFCs. At the same time, there is an energy recovery that can be exploited to supply sensors and control systems.

\section{CONCLUSION}

The remediation of environmental disasters of natural or man-made origin should be performed as far as possible exploiting natural products and elements, free of any harmful side effects. In this framework, use of MFCs represents a promising technology capable of reducing environmental pollution exploiting the bioelectrochemical process, using organic matter via microbial metabolism, to generate usable by-products, fuels and bioelectricity. At the same time, this technology has the advantage of no emissions of nonbiogenic pollutant gases.

Considering the importance of monitoring in every environmental management activity, devices like MFCs, which convert chemical energy of chemical bonds into electricity using microorganisms and organic substrate already present within the soil or wastewater, can be appropriately used to self-power sensors and electronic systems as such systems require low voltage and low power to operate. This can lead to an ever-increasing use of MFC, thus supporting the monitoring activities that are fundamental in environmental management. Moreover, the sensitivity of the energy conversion efficiency of the cells to the variations of some environmental parameters allows their use as sensors, reducing effectively the impact due to the introduction of electronic components and devices in the natural environment.

Although the analysis of power production for TMFCs and WWMFCs showed low values of voltage and power generated, these are however sufficient to power a WSN node. This can be possible if the power system of a single MFC includes a smart circuit increasing voltage as well as a capacitor. This device suitably manages the node functioning by accumulating energy to be delivered during transmission time and local data processing.

It is necessary to optimize an MFC stack configuration to guarantee higher power levels and make the technology more competitive compared to other non-nature-based energy sources, with all the listed advantages of the MFC usage. At the same time, similar optimized stack configurations are being studied with the aim of increasing the reclamation rate of polluted sites, whether they are soil or wastewater. For example, by using currently available WWMFC stacks, it is possible to decontaminate up to $20 \mathrm{~L}$ /day of wastewater generated in a coffee treatment plant, obtaining a water quality sufficient for reuse in agriculture.

\section{ACKNOWLEDGEMENTS}

The authors thank the researchers of the Ampere Laboratories (Universitè de Lyon, INSA Lyon, ECL, LYON 1) for the design and construction of WWMFC prototypes on laboratory scale.

\section{REFERENCES}

[1] Du, Z., Li, H. \& Gu, T. A state of the art review on microbial fuel cells: A promising technology for wastewater treatment and bioenergy, Biotechnol. Adv., 25, pp. 464-482, 2007. 
[2] Santoro, C., Arbizzani, C., Erable B. \& Ieropoulos, I., Microbial fuel cells: From fundamentals to applications. A review, Journal of Power Sources, 15, pp. 225-244, 2017.

[3] Brandon, E. Global approaches to site contamination law, Springer Science and Business Media Dordrecht, Netherlands, p. 378, 2013.

[4] All Persistent organic pollutants listed in the Stockholm Convention, http://chm.pops. int/TheConvention/ThePOPs/AllPOPs/tabid/2509/Default.aspx

[5] Vijgen, J., de Borst, B., Weber, R., Stobiecki, T. \& Forter, M., HCH and lindane contaminated sites: European and global need for a permanent solution for a long-time neglected issue. Environmental Pollution. 248, pp. 696-705, 2019.

[6] Limoli, A., Garzia, E., De Pretto, A. \& De Muri, C., Illegal landfill in Italy (EU) - a multidisciplinary approach, Environmental Forensics, 20(1), pp. 26-38, 2019.

[7] Watkins, E., A case study on illegal localized pollution incidents in the EU. A Study Compiled as Part of the EFFACE Project. IE, London: IE, pp. 1-36. Available at www. efface.eu, 2015.

[8] Selvamurugan, M., Doraisamy, P. \& Maheswari, M., An integrated treatment system for coffee processing wastewater using anaerobic and aerobic process. Ecological Engineering, 36(12), pp. 1686-1690, 2010.

[9] Rattan, S., Parande, A. K., Nagaraju, V. D. \& Ghiwari, G. K., A comprehensive review on utilization of wastewater from coffee processing, Environmental Science and Pollution Research, 22(9), pp. 6461-6472, 2015.

[10] Liberatore, M. J., Hozer, L., Sreeram, A. N., Kumar, R., Bindra, C. \& Fan, Z. H., Enzymatic fuel cell, U.S. Patent No. 6,500,571. 31 Dec. 2002.

[11] Rincón, R. A., Lau, C., Luckarift, H. R., Garcia, K.E., Adkins, E., Johnson, G. R. \& Atanassov, P., Enzymatic fuel cells: Integrating flow-through anode and air-breathing cathode into a membrane-less biofuel cell design, Biosensors and Bioelectronics, 27(1), pp. 132-136. 2011.

[12] E. Bååtha, E. \& Andersonb, T.-H., Comparison of soil fungal/bacterial ratios in a pH gradient using physiological and PLFA-based techniques, Soil Biology and Biochemistry, 35(7), pp. 955-963, 2003.

[13] Katuri, K. P., Scott, K., Head, I. M., Picioreanu, C. \& Curtis, T. P. Microbial fuel cells meet with external resistance. Bioresource technology, 102(3), pp. 2758-2766, 2011.

[14] Rismani-Yazdi, H., Christy, A. D., Carver, S. M., Yu, Z., Dehority, B. \& Tuovinen, O. H., Effect of external resistance on bacterial diversity and metabolism in cellulose-fed microbial fuel cells. Bioresource technology, 102(1), pp. 278-83, 2011.

[15] Pietrelli, A., I. Bavasso, N. Lovecchio, V. Ferrara \& B. Allard, MFC as biosensor, bioreactor and bioremediator, Proceedings of IEEE IWASI 2019 - 8th IEEE International Workshop on Advances in Sensors and Interfaces, Otranto (LE), Italy, pp. 296-300, 2019.

[16] Pietrelli, A. I. Bavasso, N. Lovecchio, V. Ferrara \& B. Allard, Custom measuring system tailored for MFCs, Proceedings of IEEE IWASI 2019 - 8th IEEE International Workshop on Advances in Sensors and Interfaces, Otranto (LE), Italy, pp. 264-267, 2019.

[17] Pietrelli, A., V. Ferrara, A. Micangeli \& L. Uribe, Efficient Energy Harvesting for microbial fuel cell dedicated to wireless sensor network, Proceedings of 2015 XVIII AISEM Annual Conference, Trento, Italy, pp. 1-4, 2015. 
[18] Barra Caracciolo, A., Grenni, P., Cupo, C. \& Rossetti, S., In situ analysis of native microbial communities in complex samples with high particulate loads, FEMS Microbiol Lett, 253, pp. 55-58, 2005.

[19] Grenni, P., Barra Caracciolo, A., Rodríguez-Cruz, M.S. \& Sánchez-Martín, M.J., Changes in the microbial activity in a soil amended with oak and pine residues and treated with linuron herbicide. Appl Soil Ecol, 41, pp. 2-7, 2009.

[20] Drewes, J. E., Hübner, U., Zhiteneva, V. \& Karakurt, S., Characterization of unplanned water reuse in the EU (Final Report 2017), Urban Water Systems Engineering, Technical University of Munich for the European Commission DG Environment, 2017.

[21] Pandey, P., Shinde, V. N., Deopurkar R. L., Kale S. P., Patil S. A. \& D. Pant, Recent advances in the use of different substrates in microbial fuel cells toward wastewater treatment and simultaneous energy recovery. Applied Energy, 168, pp. 706-723, 2016. 